Boise State University

ScholarWorks

Anthropology Faculty Publications and

Presentations

Department of Anthropology

Spring 2015

\title{
Linking Disparate Approaches to the Study of Social Norms: An Example from Northern Siberia
}

John P. Ziker

Boise State University

This is a post-peer-review, pre-copyedited version of an article published in Sibirica. The definitive publisherauthenticated version (2015) Sibirica, 14(1), 68-101 is available online at doi: 10.3167/sib.2015.140104. 


\title{
Linking Disparate Approaches to the Study of Social Norms: An Example from Northern Siberia
}

\author{
John P. Ziker \\ Boise State University
}

\begin{abstract}
This article examines altruistic social norms among the Dolgans and the Nganasans in Arctic Siberia, drawing on and integrating experimental game theory and semiotic approaches. The article demonstrates the complementarity of these two methodologies in order to more fully understand how sharing is promoted over individual selfaggrandizement in a communal-resource property regime. Any theory of social norms should be of some practical benefit for solving current environmental dilemmas, as well as for increasing understanding of the factors lending sustainability to human-environment relationships. With that goal in mind, the article presents results of experimental games conducted in the Taimyr Autonomous Region in 2003, along with an analysis of indigenous communication (sayings, aphorisms, taboos, etc.) aimed at the promotion of altruistic social norms. A synthesis of the two approaches is outlined with implications for the broader literature on hunting peoples across the north and beyond.
\end{abstract}

Keywords: abduction, common-pool resources, dictator game, Taimyr, traditional ecological knowledge, ultimatum game

\section{Theoretical Preliminaries}

As the scale of human groups and social networks has increased over time, the question of cooperation becomes increasingly relevant from theoretical and applied perspectives because the greater the scale, the more numerous the opportunities for defection will be. Defection occurs where the benefits of social life are taken but the costs are not paid. This phenomenon is also known as the "free-rider" problem. Where groups are large, economic differentiation ensues, profit maximization ${ }^{1}$ is justified and even encouraged, and defection on communal resource regimes, cooperative husbanding, or conservation is more likely. Many large societies have institutions and specialized occupations involved in monitoring and controlling behavior to prevent especially egregious breakdowns. Nonetheless, defection occurs, and common-pool resources, particularly those subject to externalized costs such as biodiversity, air and watersheds, are vulnerable to degradation (Borgerhoff-Mulder and Coppolillo 2005: 144). There has been a move to address "free rider" problems as "second-order collective action” problems in anthropological analyses of social dilemmas (e.g., Ruttan 1998). The second-order problem is: Who monitors and controls those whose "job" it is to monitor and control? Monitoring and control are facilitated through a variety of cultural traditions and social institutions, including property rights, social organization, government, and co- management, which have been the traditional focus in anthropology (e.g., McKay and Acheson 1987; Trawick 2001).

In the game theory literature the use of formal techniques (like economic experiments) is described and discussed as a means to study universal and foundational aspects of human social behavior (Henrich et al. 2004). This approach makes "bounded" rational-choice assumptions about participants. ${ }^{2}$ Formal techniques have a number of limitations, but a major advantage is that the results of the same protocol (properly translated) are directly comparable across societies and through time. Pure rational-choice models are problematic on a crosscultural basis, and it is widely recognized that such models are fair predictors of economic behavior only in market-based societies (Frydman and Goldberg 2007). Therefore, an assumption of bounded rationality underpins all decision-making models discussed here, as this perspective admits limits to the abilities of the human mind to calculate optimal outcomes (Girgerenzer and Selton 2002; Ostrom 2003). An experimental approach is useful for developing models of cooperation as empirically identifiable relationships between variables that can tell us something about our decision making and the factors that affect it across space and time. 
Where small-scale, indigenous societies are incorporated into large-scale societies based on industrial production, many researchers have found the continuation of communal property regimes and the pro-social norms and preferences that support them, despite the change in economic production (Barnard 2002; Bowles and Gintis 1998). The perpetuation of social norms for sharing, reciprocity, and equitable and long-term use of resources, for example, in such societies is of interest for the societies themselves, as it is for scholars and laypeople interested in sustainable economies. In order to delve into the causes of the perpetuation of social norms of sharing and reciprocity, the second line of argumentation in this article examines the logic of traditional communication about virtuous practices. I argue that this traditional communication is essential in setting up the frames of reference and social preferences that we find defining the boundaries of rational choice. While it is widely recognized in anthropology that elders and kin play a role in propagating social norms (and so there is no "problem"), the mechanisms by which norms are successfully reproduced, even in post-colonial contexts, are not yet fully elaborated.

This article addresses these collective-action problems from two perspectives, one evolutionary and game theoretic, the other focusing on the semiotics of traditional communication. These are two distinct approaches in anthropology, and are often set in almost diametrical opposition to one another. I point out the analogies and bring them together into an integrated theory. The argument is illustrated with ethnographic examples from northern Siberia along with a discussion of results from controlled experiments conducted there in 2003.

\section{Bounded Rational Choice Approaches to Cooperation}

One interdisciplinary approach that models the development of social norms from the bounded rational choice perspective is the use of evolutionary game theory to simulate various cooperation problems (Henrich et al. 2004; Roth et al. 1991). The principle research question is geared to uncovering the mechanisms and strategies used to minimize social defection and to promote cooperation. These mechanisms are discussed in game theory and evolutionary ecology, as are ideas for why such mechanisms exist at all in the evolution of social species (Axelrod and Hamilton 1981; Bowles and Gintis 1998; Nowak 2005). Researchers taking this approach commonly develop experimental scenarios, and using both human and non-human subjects (Jensen et al. 2007) observe decision making in special contexts. Cooperation problems are often modeled as some form of social dilemma - a scenario in which players cooperate or defect. The structure of the well-known prisoner's dilemma favors each player defecting ("ratting out" their partner in crime), which leads to mutual defection (Axelrod and Hamilton 1981). Other scenarios, such as the public-goods game in which participants put private tokens into a public pot, demonstrate unexpectedly high levels of initial cooperation. Such cooperation continues, especially where communication can help determine ground rules and trust (Ostrom 2003). It is clear from many different experiments that human participants are initially not likely to choose the individual income-maximizing option as predicted by a pure rational-choice model, unless no communication between subjects is allowed over multiple rounds of experiments. The boundaries of rationality provide us assumptions and social preferences that go beyond the utility maximizing solutions and decisions predicted by pure rational choice (Nash 1950).

Remembering the formalist-substantivist debate of the 1960s, George Dalton (1971) argued that it was a hopeless absurdity to equate rationality with profit maximizing or materially gainful behavior, and then to expect to find rational behavior in non-market sectors of non-Western societies. ${ }^{3}$ It is, therefore, not surprising that in experiments in 15 societies (Henrich et al. 2006), altruistic decisions were common despite relatively low levels of punishment. In other words, subjects contributed substantially more than they would have if their goal had been to maximize their income. Ironically, Dalton and the substantivists are vindicated through these very formal experiments. However, the goal of these experiments was not to look for profit maximization in nonWestern societies. The goal for using this formal technique was to determine if within-group and cross-cultural variation in response to the games was predictable with independent variables. This variation, in turn, was to help inform models of the psychology and evolution of cooperation.

At this point, one might ask about symbolic capital arguments, thinking that people are not going to maximize in the short term. Considering the sensibilities of sharing and the importance of prestige, which Mauss (1954[1925]) and Bourdieu (1977) long ago recognized in their discussions of the potlatch, maximization might come about under the pretence of altruism. In the case of the potlatch, altruists are powerful and derive prestige through their actions. As they draw on their social networks to accumulate goods to give away to others or destroy in others' presence, a leader's beneficence both requires and accelerates the political support to act as leader (i.e., to be respected and have a voice that is heard) in a wide range of situations. Evolutionary economists such as Robert Frank (1988) have developed the argument further, exploring the role of reputation in the development of moral sentiments, specifying the alternative but not mutually exclusive pathways of "sincere-manner" and "prestige." In both accounts people do not cheat when they know that there is a high 
likelihood of being caught. With sincere manners there are outward physical signs of trustworthiness. With the prestige pathway, reputation is determined by communication. The symbolic capital argument is premised on the prestige pathway for reputation building. The sincere-manner pathway has wider applicability across societies, and may have greater significance for understanding social norms in non-hierarchical and ancient small-scale human societies.

One of the common challenges to scholarly explanations of social norms that may help address phenomena such as symbolic capital is the differentiation of ultimate and proximate causation. This distinction is becoming more widely appreciated due to the development of evolutionary psychology (Tooby and Cosmides 1992). The economic experiments by Henrich et al. (2006, 2010), as well as most evolutionary game theoretically inspired writings (e.g., Frank 1988; Gintis 2000), are aimed at figuring out what factors or pressures present across cultures and over time may have favored certain types of decision making or actual mental structures and abilities that promote fairness and willingness to punish defectors. Such an approach is interested in the ultimate, or evolutionary, causes for our decision-making abilities that are manifest as behavioral-physiological adaptations (Henrich et al. 2006). In other words, from the evolutionary perspective one would expect the existence of a fit between the design features of organisms and the adaptive problems that had to be solved in the environments in which they evolved. The hypothesis of Henrich et al. (2006) is that willingness to engage in costly punishment increases as unequal behavior increases, and that the benefit (i.e., conformity to norms) is a social good or goal. An alternative hypothesis is that behavioral-psychological adaptations that promote favoring in- group members and demeaning out-group members are universal evolved human tendencies that were most likely of benefit under conditions of intergroup competition and warfare, and are necessary, but not sufficient, conditions underlying social fairness (Yamagishi and Mifune 2009). Either way, recent experiments by O’Gorman et al. (2008) showed that subjects have superior recall for normative social information in contrast to non-normative formulations, adding evidence for the theory that there is an evolved cognitive architecture relating to social norms within social groups.

These experimental approaches are quite different from historical rational-choice theories (à la Adam Smith), in which individual decisions and actions are viewed as aggregating into social structures — the market, institutions of monitoring and punishment - that work for the common good. In economics, rational-choice arguments about the origin and functioning of free market institutions have been translated into utility functions that purport to explain economic preferences and decision-making patterns all the way up to global economic development. An example of this line of investigation has to do with how incentives work to make voluntary contributions achieve "better" allocations of public goods (Palfrey and Rosenthal 1988). This is a proximate model of behavior based on a decidedly Western market-oriented theory.

Proximate causation has to do with the immediate reasons (rationale, motivations, etc.) for a particular behavior. Proximate explanations deal with the development and expression of psychological mechanisms, considering surrounding conditions and experiences that lead to particular behaviours. ${ }^{4}$ A proximate account should also include the frames of reference by which individuals in particular communities judge actions to be proper or valued.

A more recent focus in some economics circles takes into consideration individuals' social preference (Fehr and Fischbacher 2002). Social preference is invoked to explain why people do not follow rational self-interest in economic experiments, but rather prefer reciprocal fairness. Deviations from self-interest theory have a serious impact on core understandings in economics. Heterogeneity in social preferences in a population results in varied behavior in both economic games and real economic situations. This is part of a proximate explanation, but it does not answer the question of how such variation in social preferences comes about. In addition, the question of why we have social preferences at all—a question on the ultimate or evolutionary level-is not a core interest of economics.

One reason to conduct game theory-based experiments in a variety of non-Western societies is to develop models of behavior that are better informed of human variation than standard economic models. Following these cross-cultural experiments, this article aims to provide a less ethnocentric view of human decision making by indicating where the boundaries of rational choice are, and how social preferences come to develop the way they do. Additional consideration could be given to a multitude of proximate mechanisms that may include, among others, risk aversion, inequality aversion and supply and demand.

A parallel kind of proximate argument about social preferences in non-Western societies relevant when considering economic behavior in economic experiments, and the social norms and preferences that inform it, is prevalent in the anthropological literature of non-market societies (Woodburn 1998). Where economies are 
embedded in social and cosmological landscapes in which human and non-human persons promote personal relationships and social goals (equality) rather than individual material gain, the result is one of restraint on individual agency. This kind of evidence has more to do with the social context upon which decision making is predicated, and is developed as a semiotic approach in this article. This article's major methodological concern is how to synthesize the bounded rational choice and semiotic approaches on the proximate level.

As an example of one such synthesis, Polly Wiessner (2005) recently analyzed 308 conversations she recorded among Ju/'hoansi Bushmen of the Kalahari Desert to find out if altruistic rewarding and punishing in discourse plays a role in social norm enforcement. After extensive analysis of the outcomes of communication about disputes (from “communication of the message” up to "ostracism” and “violence”), Wiessner (2005: 139) found that "individuals obeyed the norm and punished its violators, even when this costly behavior could not be justified in terms of immediate selfish preferences.” The long-term benefits of costly punishment are likely to be found in the fact that the Ju/'hoansi live in "stable, cooperative, and harmonious groups" (Wiessner 2005: 139). In Wiessner's article, a synthesis is accomplished via: 1) analysis of real discourse and behavioral outcomes in terms of proximate causes, such as costly punishment, and 2) the evolutionary rationale of the mechanisms behind the selection and maintenance of such proximate mechanisms.

A similar but slightly different synthesis is proposed here. The analysis of real discourse from Siberia is preliminary and oriented toward proximate causality. The empirical results from experimental games are contextualized with the consideration of frames of reference and social norms promoted within traditional discourse. How such mechanisms and processes make sense in terms of the evolution of cooperation is also considered.

\section{$\underline{\text { Semiotic Approaches to Sharing in Non-Market Societies }}$}

One of the major interests in modern social anthropology is the maintenance of indigenous social norms in the context of colonialization and globalization (Barnard 2004). Explaining continuity in local practices (especially communal resource management regimes) of small- scale groups that are in contact with, or have been incorporated into, bureaucratic societies is an issue of theoretical significance for many anthropologists and of practical importance to indigenous groups. Continuities in social norms are usually attributed either to structural aspects of the larger social system or to individual agency. ${ }^{5}$ This, however, is a false dichotomy. Communal property, generosity and mutual aid have been observed in subsistence production societies across time and geographic areas (Barnard 2002, 2004), and many indigenous peoples are returning to, or defending, these communal traditions in the present (e.g., Fondahl et al. 2000) illustrating both structural constraints/openings and the effects of agency.

Nicholas Peterson (2002) suggests that social-economic continuities among native peoples are reproduced at a basic level through systems of social access to the means of survival. Peterson proposes the concept of the "domestic moral economy," building on his own concept of “demand sharing” with certain parallels to Sahlins's (1972) domestic mode of production and Scott's (1976) moral economy. In Peterson's perspective, infrastructure (kinship) and superstructure (moral economy) work in concert to perpetuate practices such as sharing. ${ }^{6}$

Alan Barnard (2002) proposes a further shift away from explanations focusing on mode of production (i.e., utilities), and proposes a heuristic based on the concepts of the "foraging mode of thought" and "accumulation mode of thought.” In Barnard's argument, standards and values in the different modes of thought are clearly dichotomous. For example, among non-foraging peoples accumulation of wealth is considered to be "social" while immediate consumption is "antisocial." Among foragers, the opposite obtains: accumulation is "antisocial” and immediate consumption is "social." Such values constrain or inform social behavior in each type of society to create continuities despite changes in mode of production. Barnard's work reintegrates the moral aspects of economy into the realm of political economy by pointing out the ideological limits and constraints on individual agency, but the heuristic does not explain how the ideologies are generated. In this respect, Barnard's heuristic suffers from the same problems as other structural approaches.

Thomas Widlok (2002) connects the dots between individual agency and ideological structure by focusing on virtue and virtuous practice, and developing a set of related terms to be applied across diverse cases and apparently dichotomous ethical-economic systems ("moral” through "political” economies). For Widlok, it is theoretically more productive "to focus on social agency and social relations instead of cultural rules" (2002: 13). This perspective follows Ingold's (2000) point that the "total field of relations in which individuals are situated guides the formation ofindividuals' skill and virtues. Unlike consequentialist theories that judge the 
rightness or wrongness of an action based on the consequences that action has (e.g., utilitarianism), Widlok attempts to develop a non-consequentialist theory in which rightness or wrongness of actions is judged on the properties intrinsic to the action, not on the consequences. Widlok's basic set of related theoretical terms are "action," "goal” (i.e., circumstantial good), "benefit” (i.e., classified good), and "good.” His argument focuses on how goods, goals, and benefits are communicated and demonstrated in practice. The use of such concepts brings this approach frightfully close to consequentialist/utilitarian approaches. Widlok even concedes that the "sequence "goal-practice-benefit" is reminiscent [of] idealized rational decision making which also governs exchange” (2002: 27). Although this terminological duplication opens a possible critique of Widlok's nonconsequentialist ambitions, I argue that the duplication demonstrates the need to synthesize bounded rational choice and semiotic approaches, as it shows how structures can be generated, especially those that support the norms for social/public goods.

As examples of this approach, Widlok compares his contrasting fieldwork experiences among the Hai//om Bushmen of Namibia and Kimberly region Australian Aborigines. Among Hai//om, Widlok discusses the view that sharing land and food are benefits and social goods. The practice, common in the area, is to grant access to land, much as Barnard (2002) suggests for foragers in general. Among the Aborigines, by contrast, Widlok explains that access to land is more goal-oriented (e.g., making a successful land claim) and highly restricted by the Aborigines themselves, in addition to a series of governmental and non-governmental gatekeepers. In this case, it is the goal of restriction (exclusion) that makes it virtuous. Widlok differentiates a number of facets of virtuous practice, focusing on the interplay between the use of the moral dimension and actions related to access (property). He shows how goods, goals, and benefits are used as examples of virtuous practice, leading to the development of what might be termed ideology when it becomes sufficiently standardized. Widlok admits that the 'terms 'goods,' 'benefits,' and 'goals' are not new ... [and] ... have been applied in micro-scale studies of individual subjects in (largely artificial) decision making and dilemma setting (as in psychology and part of economics)" (2002: 22). Again, this duplication could be turned toward the synthesis argued for in this article. The key to Widlok's argument differentiating the non- consequentialist theory of social norms is his point, following Gell (1998), that goals, benefits and goods are "abducted” from virtuous practice in real behavioural settings. But what is abduction?

American philosopher Charles Sanders Peirce, a great logician of the nineteenth century and father of semiotics, argued that in addition to deductive, or necessary inferences, there are two utterly distinct classes of probable inferences: inductive inferences and abductive inferences, which he also called "retroductive" inferences. ${ }^{7}$ An inference - best known in the form of a syllogism — consists of two premises constituting the antecedent of the inference, from which a consequent can be causally inferred by implication.

In a deductive (demonstrative) inference the consequent is derived from the antecedent and the result is necessarily true: "All balls in this urn are red (the rule); all balls in this particular sample are taken from this urn (the case); therefore, all balls in this particular random sample are red (the result)" (Burch 2010). Deductive arguments usually begin with a major premise (a rule), state a minor premise (a case of that rule), and infer the conclusion (or result). The sign “>” is used to represent the inference (see Paavola 2004: 252).

There is evidence that the human mind is suited to a particular type of deductive inference. Evolutionary psychologists Leda Cosmides and John Tooby (1989) demonstrated that subjects understood and correctly applied the deductive process - in the form of the Wason selection task-with significantly greater reliability when the rule "If P, then Q" was contextualized as a social exchange scenario. Such selection tasks are often found in descriptive or abstract forms on standardized college entrance exams where a test taker is to pick an option that needs to be checked in order to see if a rule was violated. The improved results for social exchange contexts stood even when Tooby and Cosmides used unfamiliar rules, such as, "If a man eats cassava root, then he has a tattoo on his face" (e.g., "If you take the benefit, then you have fulfilled the requirement"). When people defect on a social exchange they are taking a benefit without fulfilling a requirement. In this case, defection means eating cassava root when not tattooed (i.e., if P, but not-Q). Checking the not-P (not eating cassava) and Q options (tattooed face) are obviously not necessary to see if the rule is violated. Tooby and Cosmides (1992) explain the high performance on the contextualized Wason selection task (i.e., checking the P and not-Q options) as the result of a "look for cheaters" psychological mechanism. Further, Tooby and Cosmides argue that such universal cognitive architecture is the result the importance of social exchange over a significant fraction of hominid evolutionary history. To illustrate their point, Cosmides and Tooby (1989: 92) show that adult subjects, and standardized test takers, are generally not good at Wason selection tasks that are descriptive or based on permission rules. An example is the rule, "If a person has a ' $\mathrm{D}$ ' rating, then his documents must be coded ' 3 .'” According to their argument, humans are not good at abstract logic that has no social contract context. Presumably, according to this ultimate (evolutionary) argument, the social contract 
context was a significant enough selection pressure (i.e., benefits of cooperation vs. costs/risks of social exchange with cheaters) among our ancestors that specialized decision-making abilities were selected for, and these have been maintained throughout human history along with the importance of social exchange. An appreciation of this evolutionary background of the psychology of social exchange is relevant for the discussion here, as our logical capabilities are not determined culturally, but are efficient with regard to particular social problems, namely social defection.

Although the deductive abilities relative to cheating on social exchange address the "free-rider" problem, they do not address the question of the role of agency in the creation of social norms. This is where nondemonstrative inferences come into play. Compared to deduction, abduction is a "synthetic inference" where the antecedent is affirmed from the consequent (Gell 1998: 13-14). In other words, abductive inferences switch the case with the result (Rule \& Result > Case). Paavola (2004) likens abduction to hypothesis formation. An example of abduction using the same concepts would read: "All balls in this urn are red; all balls in this particular random sample are red; therefore, all balls in this particular sample are taken from this urn" (abduction). Abduction leaves open the possibility that a smiling person cannot or will not be friendly, and thus requires faith that the smile is a good index of friendliness. Gell (1998: 13-14), building on ideas developed by Peirce, states that an index is “a 'natural sign,' that is, an entity from which an observer can make a causal inference of some kind, or an inference about the intentions or capabilities of another person.” Indexes are signs the meaning of which can be abductively inferred. Further, Gell (1998: 14), citing Boyer (1994: 147), points out that abduction is a basic mechanism that allows people to constrain the possible number of explanations compatible with any event. This is a suggestion for the hypothetical adaptive significance of the abduction ability in the human psyche. Unfortunately, there is scant reference to abduction per se in the evolutionary psychology literature in comparison to the deductive process. Gerrans (2002: 311), citing Bloom and German (2000), makes reference to "a global cognitive capacity for abduction and inductive confirmation." Bloom and German do not mention abduction by name but mention "a sophisticated ability to reason about the mental states” (2000: B29). The approach taken below is much more descriptive and exploratory than that which would be taken by evolutionary psychology; however, controlled studies on abduction could be a potentially fruitful area of study.

Induction - the second, and more familiar, type of non-demonstrative (probable) inference-makes observations into theories, taking the deductive syllogism and interchanging the result with the rule (Case \& Result $>$ Rule) to produce: "all balls in this particular random sample are red ; all balls in this particular sample are taken from this urn; therefore All balls in this urn are red." This is the rule-building process for a descriptive rule. As we all know, smiles can be deceptive, but as a general theory to be tested, the inductive inference is a good start. There is good evidence from psychology that inductive skills in the form of probability judgments are also improved by contextualization (Blok et al. 2007).

\section{Ethnographic Context}

\section{Fieldwork Experience}

My fieldwork in Ust'-Avam totaled 30 months between January 1994 and March 2003. I spent an additional 18 months in the regional capital and three small communities in the Taimyr Autonomous region, beginning in 1992. I conducted dictator and ultimatum games in Ust'-Avam in 2003. The long-term nature of my research in the community and familiarity with many households helped to build acceptance of the experimental games, and contributed to the overall success of the experiments. A number of participants regretted that such games were not a regular social event sponsored by the village. In addition, my fieldwork in the community allowed me to identify a variety of interesting local explanations of events (ranging from good hunting fortune to untimely deaths) that provide examples of non- demonstrative inferences from social exchange rules.

Ust'-Avam is 250 kilometers from Norilsk, the largest city in the Taimyr and a vast mining and metallurgy center. As Ust'-Avam is one of the closest native villages to Norilsk, it was selected as the site for the establishment of a gospromkhoz (government hunting enterprise) in 1971, known as GPKh Taimyrskii. This would ultimately have a profound economic impact on the village. The people of Ust'-Avam have a mixed subsistence economy in which hunting, fishing and trapping form the basis of food production and distribution, while salaried work contributes to the ability to purchase consumer goods and services. ${ }^{8}$ 
This is an author-produced, peer-reviewed version of this article. The final, definitive version of this document can be found online at Sibirica, published by Berghahn Journals. Copyright restrictions may apply. doi: 10.3167/sib.2015.140104

\section{The Importance of Common Pool Resources in Ust'-Avam}

My ethnographic studies among the Dolgans and the Nganasans during the 1990s (Ziker 2002) described the increased importance of the local subsistence economy following the collapse of the Soviet planned economy in 1991. The costs of transportation have increased dramatically, and now only the most essential goods and fuel are shipped to the community. Occasionally helicopters are sent to the community for medical emergencies or the transportation of teachers. The helicopter most often used is the Mi-8, which can hold 20 passengers or up to three tons of cargo (for example, 50 reindeer carcasses). During my first visit to the region in 1992, flights were scheduled three times per week and cost less than US\$20. Now a one-way ticket costs approximately US\$250 per individual plus baggage (1 percent of the ticket price for each additional kilogram exceeding 20 kilograms). The stated income of most participants in the 2003 experimental study ranged from US $\$ 0$ to US\$5,516 annually, with a mean of US\$1,256 for all participants.

Alongside the economic depression and emergent subsistence economy in remote communities since the early 1990s, presidential decrees and regional edicts favored a variety of forms of property in the region. "Familyclan" holdings were ostensibly ordered as an immediate measure for protecting the economic independence of the indigenous people. In 2003, 163 enterprises were registered, according to a regional report. Previous archival research of 140 land allotments granted between 1992 and 1997 (48 of which were registered to indigenous residents) showed that most are located in close proximity to either the regional capital (Dudinka) or Norilsk, or along the Enisei River (Ziker 2003). Those people living in native communities at a distance from Dudinka, such as Ust'-Avam, and in remote isolated houses across the tundra, were less likely to make formal land claims. The Avam tundra has 1 registered "family-clan" holding out of 21 named hunting territories (assigned to sets of hunters, or "brigades," during the Soviet times). The territory of the one holding is rarely used because it is distant from the village. The remaining 20 territories are ostensibly held by former brigade members and are mainly used for subsistence activities. Informal means of regulating access to and distribution of resources were documented in the community. Relevant to the informal property system are the altruistic social norms.

Surrounding the village, the common-pool hunting and fishing territory (liubitel'skoe ugod'e) became more important as hunters and other workers were laid off in the 1990s. The borders between the common-pool territory and assigned hunting territories have become increasingly flexible and porous since the cessation of planned hunts in 1993. Cooperative economic activities, such as joint fishing, reindeer hunting, hauling and travelling, keep alive the time-honored tradition of "mutual aid" (Barnard 2004). As machinery became hard to replace, hunters began traveling more often on foot or on skis, and individuals needed to work out among themselves where they would be "sitting" for a season or trip. Extremely distant territories, more than 150 kilometers from the village and not located on major waterways, have fallen into disuse. Traditional management strategies in the Avam tundra address the classic collective-action problem: how to identify and exclude those who do not contribute to the provisioning or viability of critical resources. Without the ability to exclude those who degrade a resource, future communal use is placed in jeopardy. Resource distribution is controlled by and targeted at specific individuals and families. Elders and wives are the most common recipients of food. They usually have the acknowledged responsibility to redistribute it again to others, and often hold the keys to storage closets and sheds. In Ust'-Avam, social boundaries and permission requirements are used to reject individuals who have taken an extractive or abusive approach to resources in the area. These actions are justified through communication and acceptance of inferences from social exchange rules discussed below.

\section{Methods}

\section{The Experimental Background}

The ultimatum game and the dictator game were administered in Ust'-Avam during a January-March 2003 field trip sponsored by the Max Planck Institute for Social Anthropology. The player information sheets and game scripts from a U.S. National Science Foundation project ${ }^{9}$ were translated into Russian with the assistance of local Russian speakers and checked for accuracy with local assistants. The village administration supplied complete census information for the community as of 2002, including household affiliation, in the form of a numbered list. There were 163 households in the community. One adult was chosen from every third household on the list in order to arrive at a representative sample. Some people were not present, so several additional adults were recruited, first from the selected household if possible, or from the adjacent household on the list if no one from the selected household was available. One player was hard of hearing, and could not understand the instructions, so was sent home. Thus there were 59 players in the sample, all of whom understood Russian (the language in which the experiment was conducted). The director of the village school agreed to let me use 
several rooms on a Saturday and Sunday for the games. Two teachers and their husbands, all of whom are representatives of the local indigenous population, agreed to be research assistants. Basic socio-demographic background data sheets used across 15 fieldsites (Ensminger and Henrich 2014) were filled out with the assistance of the research assistants. One research assistant agreed to read the script to each of three groups, while her husband conducted the individual games in a smaller room, and I filled in player data forms recording individual decisions in the games. We videotaped several hours of the process. Summaries of the games follow.

\section{The Dictator Game}

In this scenario, there are two players. Player 1 is allotted a sum of money. In this case, it was 100 rubles (approximately US\$3.30). Player 1 is asked to divide the money, and to give any amount from zero to the full amount in 10 percent increments to an unknown Player 2 from the subject pool. Player 2 is not allowed to reject the offer; hence Player 1 is a "dictator." This "game” is essentially a one-sided and graduated social dilemma, and the results are thought to provide an estimate of the baseline generosity (trust) of participants in the subject pool, since there is no consequence if Player 1 maximizes his or her winnings by allotting nothing to Player 2.

\section{The Ultimatum Game}

The ultimatum game is similar to the dictator game, except that Player 2 may reject Player 1 's offer. It is essentially a one-shot social exchange problem. Players are told that if Player 1's offer is rejected when the anonymous participants are matched at the end of the session, then neither player wins any money; hence the ultimatum is a punishment costly to both players. Before hearing Player 1's offer and in order to determine the results for all possible offers, Player 2 states whether or not he or she would accept each of the possible offers (in 10 percent increments) an anonymous Player 1 might make. The lowest amount that Player 2 will accept is the minimal acceptable offer (MAO), which is used in aggregate to estimate the population's willingness to punish unfair offers at their own expense.

\section{Results}

Experimental Results and Variables: Dictator Game

Overall, in the Ust'-Avam dictator games (DG) the mean offer was 37.3 percent of the stake, and the mode, or most frequent offer, was 50 percent. However, the second most frequent offer was 10 percent. The distribution of the data from Ust'-Avam suggests a high level of generosity by most, and a lower level of generosity (and tendency toward income maximization) for a minority. ${ }^{10}$ The degree to which individual players had involvement in the larger economy gives equivocal information because, on the one hand, access to cash positively affected Player 1 offers while, on the other hand, the number of wealth items listed by Players 1 negatively affected offers. Players' individual cash income variable was the strongest predictor of dictator game offers in Ust'-Avam: those participants acting in the capacity of Player 1 who had lower average incomes ended up making lower offers, while those with higher incomes made higher offers in the game. Sources of income in Ust'-Avam included, for example, pensions, single-mother payments, and salaries from employment in the school or other service sectors, as reported on the player information sheets. This relationship suggests that the greater the involvement in the larger economy, the closer offers approached 50 percent (i.e., “fair”). Eighty percent of participants made significantly higher offers than would be predicted by rational-choice theory, which predicts offers close to zero percent.

Micro-social conditions, specifically household size, influenced dictator game offers. Participants from larger households were less generous, possibly because they perceived greater need for every kopek, or perhaps because they would normally share with more individuals on a daily basis and they therefore take as much as they can get when given the opportunity. A similar negative relationship to offers was found in dictator game experiments among undergraduate college students at Boise State University in 2005, where a statistically suggestive trend showed those living in larger households and with more non-kin roommates made lower offers in the dictator game (Ziker et al. 2006). The possibility that household size affects offers in similar ways across cultures is intriguing and suggests an influence of social factors on calibrating human psychology.

Wealth was negatively related to dictator game offers in Ust'-Avam, but statistically this was a weak finding. Wealth was estimated as a raw count of material items, such as snowmobiles, boats, motors, firearms, and sewing machines, listed on the player data sheet. A confounding issue is the fact that most individuals accumulated wealth items during the Soviet era, when such items were more plentiful and accessible to hunters 
and their families through mail order and the state enterprise. The correlation between wealth and lower dictator game offers suggests that people who had a more selfish disposition were more likely to have accumulated durable goods in Soviet times (based on ethnographic observations over a decade). It therefore makes sense that raw counts of wealth items did not correlate with income in 2003. Other variables investigated across these experimental economic studies, including age, sex, years of education, and five other market-integration variables, were not significant in regressions of dictator game offers in Ust'-Avam. The number of examples given to the respondent in the individual round was related positively to offers, suggesting that those who needed practice to demonstrate their understanding of the zero-sum implications of their decisions trended toward equitable divisions.

\section{Experimental Results and Variables: Ultimatum Game}

The most frequent ultimatum game offer in Ust'-Avam (made by close to 60 percent of Players 1) was 50:50; average offers were slightly lower (48 percent). Mean offers hovering around 40 percent in the ultimatum game (UG) with the mode at the 50:50 split is characteristic of studies of university students and Western societies (Oosterbeek et al. 2004). Mean and modal offers in Ust'-Avam were in the middle of the range of findings by Henrich et al. (2004) for a variety of non-western societies. In Ust'-Avam, 15 percent of the ultimatum game offers were 20 percent or less. Seven percent of the UG offers were 60 percent or more. With a single mode at 50 percent, the results had a normal distribution. Nonetheless, there were no independent variables that predicted ultimatum game offers except a very weak positive correlation to DG offers - similar to other cases in the crosscultural data (Jean Ensminger, personal communication). It might be hypothesized that in the UG scenario there is enough apprehension about the possibility of rejection (and loss of all possible winnings) to channel players' allocation decisions to even splits.

Exploring participants' willingness to punish unfair offers, Players 2 were asked to respond to each potential offer (from zero to 100 percent) they could have received from Player 1 in the UG. This information provides data for identifying each individual's MAO. The MAO provides a glimpse into the perspective of individuals on the receiving end of this social exchange scenario. The average MAO for the Ust'-Avam experiments was 16.6 percent of the stake (number of Players 2 = 29). For comparison, the average MAO for 2005 experiments at Boise State University was 25.5 percent (number of Players 2 = 11). Kahneman et al. (1986: S291) report average MAO of 25.9 percent in experiments with psychology students at the University of British Columbia. The MAOs in Ust'-Avam are significantly lower than those found in these Western settings, indicating less of a concern for even splits by Players 2. This result indicates that people in Ust'-Avam expect generosity without the need for high degrees of punishment. In other words they appear less vindictive in this experimental setting.

Household size was negatively related to MAOs. In other words, individuals in larger households were willing to accept lower offers. This might be due to the fact that people in larger households share with a larger number of people on a daily basis, and this reflects the likelihood that they will accept smaller portions of collective pies regularly. Remember that household size affected offers in the dictator game, so that individuals living in larger households made smaller offers. This is an interesting parallel, indicating parties on both sides of the experiment have applied similar social norms. Age is not correlated with household size, so these variables do not appear to be covariates. ${ }^{11}$

Overall, with the ultimatum game, Player 1 offers were highly geared toward fairness, but rejection rates were relatively low and income maximization for Player 1 would have occurred at 10 percent (Henrich et al. 2006). Players were offering more than they could have without risking punishment. This arguably represents a high degree of pro-sociality in the community which conforms to the ethnographic data on food sharing, land use, and world view (Ziker 2002).

\section{$\underline{\text { Interpretation of Experimental Results }}$}

If one assumes the strong definition of rational choice, the experimental results in Ust'-Avam echo those of other societies where individuals appear to be making suboptimal decisions - they are not maximizing when they could especially considering that rejection levels (MAOs) are relatively low. This suggests that social norms for equity are consistent in Ust'-Avam and applied in this experimental context, and that direct tit-for-tat punishment is not used as consistently in the UG experiment as it is by players in Western market-based societies where rejection rates are usually high. The fact that player income in Ust'-Avam affected offers suggests that integration with the greater economy increases equitable decisions both here and in experiments other societies (Henrich et al. 2004: 32; Henrich et al. 2010). Integration with the larger economy itself could encourage expectations for equitable divisions in these experiments because of institutional concern for fairness 
and the occurrence of tat-for-tat reciprocity, which in larger economies could translate into consumers making alternative future choices (Frank 1988: 174; Fehr and Schmidt 1999). The expectation is present on both sides of the social exchange, and this is reflected in high offers by Players 1 and high acceptance of low offers by Players 2. In Ust'-Avam there is an expectation of fairness, but the willingness to punish is less than that found in Western societies and communities with greater market participation. The low incidence of low offers in the ultimatum game and moderate levels of punishment that occurred in Ust'-Avam may reflect the goals and values propagated in the subsistence hunting economy, with its common-pool territories, common sharing with kin and sense of entitlements to aid for community members.

Micro-social contexts and independent attributes of players, such as attendance at religious services—with a positive effect on DG offers just out of range of statistical significance-also affected decisions in the games in Siberia. Increased household size was related to both lower offers by Player 1 in the DG and lower minimal acceptable offers from Player 2 in the UG.

These micro-social factors suggest that there are life-cycle related sources of variability in economic behavior and local social norms, a finding that is supported by early economic and processual anthropological research showing that life-cycle variability is related to household size (Fortes 1958; Sahlins 1972). One anecdotal bit of evidence of life- cycle variability relating to social norms in Ust'-Avam surrounds taboos expressed by elders. In the early 1990s I observed younger adults expressing disbelief at some taboos; however, when they later became parents, they used similar rhetorical devices to direct their own children's behavior. This acceptance of what is offered-rather than a heightened concern for equity-may qualify as a virtuous practice in larger households in Ust'-Avam. Such practice is isomorphic with philosophies of this and other hunting-and-gathering societies where the environment is viewed as a giving entity, but it raises intriguing question: How is it possible to explain the high degree of pro-sociality found in hunting and gathering societies without the heavy reliance on punishment?

\section{Non-Demonstrative Inferences and Social Norms}

A number of aphorisms, cosmological concepts, and ideas about the relationship between humans and their environment are prevalent in Siberia among the Dolgans and the Nganasans, and across indigenous peoples in the circumpolar North. An example from Ust'- Avam is the "law of the tundra," a multifaceted social contract between the people and the spirits of the tundra, containing admonitions for mistreating flora and fauna and prescriptions to help others. The goods, goals, and benefits to community members are abducted from virtuous practices or stories of virtuous and unvirtuous practices indexed as the "law of the tundra." These ideas are repeated by elders and others in the community in a variety of contexts (see, e.g., Ziker 2002: 111-115 for Oksye's story of the reindeer herder falling into the Underground Kingdom because he took his family away from other Dolgans). Ziker (2003) discusses the implications of some of these concepts for property relations in Taimyr, as does Anderson (2000). A series of adages related specifically to food sharing is discussed in Ziker (2007) and Ziker and Schnegg (2005).

An example of the link between non-demonstrative inference and social norm establishment is the relationship between discussions of hunting/fishing practices and the social good of resource conservation among the Dolgans and the Nganasans in Ust'-Avam. Many hunters in Ust'-Avam mentioned to me that they wanted the animals to be healthy and to reproduce for their children's future hunting and fishing. They explained some of their hunting and fishing techniques as satisfying this social goal of conservation, for example letting the majority of a herd (tabun) of wild reindeer (dikie) pass before starting to shoot. Beyond the obvious proximate goals of hunting and fishing to provide benefits for family and community, long-term conservation is seen as a good resulting from this virtuous practice.

People and events are discussed in light of such expectations about virtuous practices using abductive inferences (Rule and Result > Case). A formalized example with a switched social contract rule ("If I satisfy the requirement, then I take the benefit") would sound like: "If hunters treat animals with proper respect and intensity, then the animals will return (Rule); these animals returned (Result); therefore, the hunter treated the animals respectfully (Case).” Statements about treating animals with respect during hunting, butchery and distribution so that they will return are common in Ust'-Avam. Such discussions are indicative of the social contract that people have with animals through the "law of the tundra." Ideas about social relationships with animals are widespread across the circumpolar North. For example, for the Cree of Canada relationships with animal-spirit bosses (pawākan) and prey are fundamental to their philosophy (Brightman 1993: 93, 187). It is my contention that abductive inferences from such social exchange rules are communicated to affirm the virtuous practices of individuals in the community, thus "reproducing” social norms. 
A specific example from Ust'-Avam is a situation in the 1990s when gospromkhoz plans for rock ptarmigan (kuropatka) were canceled. In the 1970s and 1980s hunters were rewarded with new snowmobiles from the gospromkhoz if 1,500 rock ptarmigan were turned in. Good hunters shot kuropatka with small calibre (5.62 mm) rifles. According to one Dolgan hunter discussing rock ptarmigan hunting and trapping, plenty of the birds circulated when hunters paid attention to them, even with the intention of hunting them. This was how they "fulfilled the requirement" of showing the requisite respect for and interest in the birds. During Soviet times, the birds were treated with the right amount of respect and interest, and thus the hunting was a virtuous practice. In the 1990s, after state-sponsored hunting collapsed and this incentive program was abandoned, people stopped hunting rock ptarmigan and the birds mysteriously disappeared. The reason given to me for their disappearance was that hunters stopped paying attention to the birds (i.e., the requirement was not satisfied). If one gives credence to the abductive inference above, the statement makes perfect sense because the animals did not return and we know that the birds were not treated with proper respect and hunting intensity (i.e., they were ignored).

More recently, when food has been short in the spring, young hunters have been setting up snares in a series of routes (trap lines) in riparian areas within walking distance of the village. These hunters have been successfully bringing home rock ptarmigan almost every time they check their traps. Rock ptarmigan are again being paid attention to and so they have returned in good numbers. This narrative shows that people in the community perceive and communicate their relationships with the environment, and their understanding of their role in the local ecological system, and that a certain amount of hunting is more virtuous than not hunting at all. A deductive interpretation, of course, is that when people are not hunting, they are less likely to notice the birds, so it would seem like there are fewer birds around.

In this light, specific events are discussed and interpreted in the community as evidence of the deviation from virtuous practice. Traditional rules that promote adherence to social norms are likely developed (induced) in this way: a hunter is known for overhunting, or the improper non-virtuous use of resources on his territory: one of the hunter's relatives (or the hunter himself) dies prematurely following the improper behavior. This premature death can become associated with the hunter's actions in the tundra to induce a rule: if people hunt without proper respect and intensity, that is without virtue, people may die as a result of supernatural retribution. The death is associated with the hunter's non-virtuous use of resources through inductive inference. In reality, such cases and results are discussed and debated within the community, and narratives are established which embed the event in a wider social logic that bolsters social norms. When the non-demonstrative inference is promoted by elders and accepted by middle-aged and younger people, then that acceptance is a reaffirmation of the community's traditional authority functioning to promote social norms, goods and goals. The proximate benefits (i.e., social cohesion or protection of ecological balance) of these social goods and goals are promoted through abduction to specific cases. The goods and goals are abducted from rules about virtuous practice; the rules themselves are developed through induction.

Another example of an abductive inference shows how elders typically use this form of logic to index the attributes of others, particularly youth, and to influence the behavior of younger generations. The context of this example is from a conversation between some middle-aged friends discussing the capacities of one of the many grandchildren in the presence of elders and other grandchildren: being quick (shustryi) is an important quality of being a good hunter (Rule); K. is a quick boy (shustryi mal'chik) (Result); therefore, K. will be a good hunter (Case). The case is inferred (abducted) from the rule, given a specific result. Such a statement has the tenor of a deductive prediction. However, this "prediction" is based on the logical fallacy of affirming the antecedent from the consequent and yielding conclusions that are not necessarily true. In contrast, a deductive inference would run: good hunters are quick; $\mathrm{K}$. is a good hunter, therefore, $\mathrm{K}$. is quick.

Many of the aphorisms, concepts, and identities that are characteristic of Dolgan and Nganasan social organization are ecological or relational in nature, but some directly deal with personal relationships. For example, Gracheva (1983: 52) uses the etymology of the Nganasan word for "life"-a complex set of concepts meaning "life continuing itself, sometimes called together (arranged), and placed"-to illustrate these relationships. The life force, or nilymty, extends beyond the person. It is in all objects and essences the person touches or connects with, such as clothes, smells, names, inspiration, speech, songs, dances, actions, foraging trails, housing and children. The connections are like unseen threads. Even if humans are not monitoring social contracts, the implication is that spiritual forces are monitoring human action.

In one of Gracheva's examples, a man finds a stone in the stomach of a fish he has caught. This unusual event is taken to mean that the Sea-Mother "selected" him, and sent him her "hypostasis," or essential substance, her "child, which is continuously connected with her" (Gracheva 1983:54). The hunter takes the stone home and it is seen as a good omen. He and his family members dress the stone in clothing that his wife sews, which 
provides a direct connection to her. The stone is fed, carried along in a special sled, and covered with furs. This "child" is next to the hunter and his family, sharing with them its life, although it has an independent existence. The family members talk with the stone, rouse it from sleep by the careful tap of a ceremonial stick, and convey their requests to it. If they have the impression that the stone is not helping them in fishing, ignoring the stone would only make matters worse because it connects the owners with the Sea-Mother. They can leave it with someone for safe keeping, but to give it away would have potent consequences. The very best situation would be for someone to ask for it, and for the owner to decide to give it to the person who requested it; in that case the hypostatis itself expresses the desire to go to another hunter. The Nganasan concepts of nature and person show us the importance of fictive kinship, where the people conceptualize their connections with the environment and follow the consequences of their actions with regard to it. The ultimate owner is the Sea-Mother, and the people are allowed to possess resources as long as they treat them correctly, which includes the virtuous practice of sharing, symbolized by the care of the child adopted from the Sea-Mother.

Food and other resources from the tundra are distributed widely through social networks within the Ust'-Avam community. A number of hunters stated to me that if they did not give food to other people, then successful hunting in the future would be jeopardized. "It is that kind of nature," said one hunter. Greed does not pay, in other words, and sharing with others is adduced as proper and moral social benefit. Many types of people are included in the distribution networks: relatives, friends, pensioners, single mothers and other people who request help. Because of the distribution of raw food products, accumulation is socially limited. Virtuous practice of sharing food (both raw and cooked) is abducted from the rule that correct treatment of animals (i.e., sharing the meat) brings on continued luck in hunting. These ideas have important implications for the moral dimension of cooperation and resource use because, where there are threads, actions can be traced back to individuals' actions. Inductive and abductive inferences, therefore, are used to compare actions and statements to virtuous practices in emphasizing goods and benefits for the community, rather than individual goals and actions. When everything a person touches is connected back to him or her, autonomous, individual action is in fact bounded.

\section{Summary and Conclusion}

Rational choice and semiotic approaches provide complementary explanations pointing in the same direction. Non-market based norms of sharing and reciprocity are stable in a small-scale society, even where altruistic punishment is less intense and people are more accepting of unfair divisions of a stake. The stability of such norms of sharing and reciprocity obtains through the widespread use of non-demonstrative inferences and a degree of costly enforcement (people with more offspring were less willing to accept low offers), although not as prevalent as in Western societies. Such inferences highlight social goods and associate antisocial behavior through real and mytho-historical rites of passage and tragedies. A weakness in using these two very different forms of analysis is no direct causal linkage between the use of non-demonstrative inferences in daily communication and the high baseline generosity and relative willingness to accept low offers in the experimental games. The results of the games are more in line with an index of social norms, rather than any kind of measurement of real behavior.

Experimental results indicate high basic levels of altruism in societies with strong subsistence economies such as the Dolgan and the Nganasan societies. This is demonstrated by a wide gap between minimal acceptable offers and modal offers in the ultimatum games, meaning that people are more altruistic than need be, but also that the expectation for fairness is relatively low. Where integration with the larger economy is greater, such as in many Western societies, the expectations for fairness are also greater. This relationship is counter- intuitive in that one might expect that greater experience with the larger economy would cause people to be more selfish. In fact, the results of this study and others in the NSF project (Henrich et al. 2010) indicate that experience with the larger economy encourages fairness, because players intuitively know that other players will not accept low offers. (This could be interpreted as a form of selfishness.) Such reciprocal fairness is indicative of social preferences defined by experiences in larger-scale societies. Information on players' households demonstrated that personal living situations affect generosity in these experiments. These results repeat the findings of Henrich et al. (2004) for fifteen small-scale societies. Some structural and material factors, thus, have been shown to influence sharing patterns across cultures (i.e., individuals with certain attributes appear to be more altruistic in promotion of social norms).

Abduction and induction, as discursive strategies, are used to set limits on agency in Ust'-Avam, and it can be argued that they are used for that purpose everywhere in human societies, although the exact tenor of social preferences can vary (from more altruistic to more reciprocal fairness). Non-demonstrative inferences are probability statements (Carnap 1946). When acceptance of such statements is communicated without 
skepticism, people communicate something: respect for, agreement with, or a positive association with the speaker of the non-demonstrative inference. Such inferences can be used to put into effect cooperation through a sincere-manner pathway: probability statements about the reality of cosmological reckoning in social contracts, followed by the communicated acceptance of such statements by others in the community. Induction is the development of theories and rules on the basis of observation. Abduction is the process of hypothesis generation-taking rules and results with the goal of explaining cases. Using both forms of communication, a speaker can develop rules or explain events that illustrate virtuous practices, and, in the context of social exchange rules, reproduce social norms for kin-like altruism within the community.

Ethnographic study among the Dolgans and the Nganasans during the 1990s (Ziker 2002) described the increased importance of the local subsistence economy after the collapse of the Soviet planned economy. The development of communal social organizations, common-pool resources, and heightened non-market exchange during the post-socialist period appears to promote social goals of equity that subvert individual goals. A closer analysis shows that traditional communication about virtuous practices and social norms sets the frames of reckoning with regard to individual behavior and its rationality. Individual actions that emphasize social goals and public goods to the extent they do among the Dolgans and the Nganasans may appear suboptimal in the context of pure rational choice and free- market global economies, but are entirely within the bounds of rationality in this social context that individuals create and recreate every day.

\section{Arguments and Synthesis}

In this article I have argued that formal approaches to human economic behavior are useful in testing the relationships between observations and independent variables. Such studies provide comparative material for developing hypotheses about the role of individual decisions and empirical variables on communal action problems, such as maintaining social norms. This approach has uncovered measurable factors contributing to fairness, which may be ultimately related to the sustainability of small-scale economies. Such cultural continuities may seem irrational or outdated to the outsider or non-specialist. Nonetheless, these factors may also be of interest to those looking into questions about the evolution of human sociality, particularly the maintenance of social norms in societies without systems and institutions for formal social control.

I have also argued that in order to understand the development of specific examples of social norm maintenance (e.g., communal sharing after the collapse of the Soviet economy in Siberia) one must also understand the traditional communicative practices and social processes that set goals, values, or standards. Maintaining Widlok's call for developing an analytical scheme useful across ethnographic cases, one might expect to find a variety of non- demonstrative inferences targeted at maintaining authority in one society and egalitarianism in others. Social structure (limits on agency) in this perspective is not a template existing "out there" in the collective unconscious, but is the behavioral result of individuals involved in communication and acceptance of language that reflects mutual respect, influence, and authority. Similarly, Karp (1986) uses the concept of agency in a general sense that emphasizes the relevance of factors other than self-interest, such as knowledge, consciousness and personhood. Gell also emphasizes social agency in his definition of art: the presence of an index from which abductions are made (1998: 15). Gell goes beyond aesthetics, and argues that art is a process in which recipients abduct relations between persons and things from indexes (objectifications) created by the artist. The law of the tundra is one such index within social discourse among the Dolgans and the Nganasans.

This article is an effort at creating a synthesis between rational-choice and semiotic approaches by demonstrating that they provide complementary explanations pointing in the same direction. This is an argument to integrate ultimate and proximate lines of argumentation. For example, the experimental results indicate high basic levels of altruism in Ust'-Avam, as in other societies with subsistence economies. Among the Dolgans and the Nganasans, where punishment levels were moderate, certain material factors such as income and household size still affected offers and rejection patterns in the games. These patterns can help us to understand the importance of elders and parents in encouraging cooperation through non-demonstrative modes of communication. Acceptance of such communication reflects mutually agreed on limits to egoistic behavior. Such traditional communication is not a social structure acting as a template to determine behavior, but is a tool used to bolster cooperation through positive and negative examples of virtuous practice. As such, individual advantage may obtain in the form of risk reduction in subsistence or consumption, or coalitional support within social networks, providing an individual-level pathway for the evolutionary psychology of norm promotion and enforcement. 
This is an author-produced, peer-reviewed version of this article. The final, definitive version of this document can be found online at Sibirica, published by Berghahn Journals. Copyright restrictions may apply. doi: 10.3167/sib.2015.140104

\section{Discussion: An Integrated Approach}

Anthropology is widely argued, especially by American anthropologists, to be a holistic enterprise that attempts to bring in multiple lines of evidence and inquiry in order to develop a broad understanding of the human condition and human origins. This article follows in that tradition by bringing together two rather disparate approaches to the question of social norm perpetuation. The gap between these two approaches is closed by taking a step back from the problem and considering the interplay between proximate and ultimate levels of explanation. The semiotic approach is much more interested in the proximate causes of behavior, in this case the perpetuation of social norms in small-scale societies. The non-consequentialist approach looks at forms of communication and how examples (cases) are the result of a particular rule. Developing a language to analyze communication, including art, across ethnographic cases has much potential. Much of what goes on in all human societies is more political and social than economic in the strictly rational decision-making sense. The semiotic approach is a way to understand the dynamics of individual action in a field of relationships. One might argue that approaches that try to consider the consequences make problematic assumptions or have problematic methods of measurement. However, if one takes this position without careful consideration, the evidence from experimental psychology and other interdisciplinary efforts that study the same kind of phenomena (i.e., social norms and contracts) would be excluded from the anthropological club. The vocabulary of these efforts is strikingly similar to the non-consequentialist position (i.e., goals, goods, benefits). So why not make the connection explicit? Anthropology is positioned to make contributions to broad understandings of social norm perpetuation, particularly as it relates to common-property dilemmas, but we have to engage.

The evidence from experimental studies indicates that humans are strongly predisposed to look at each other's behavior in terms of social norms and social contracts. There is a good deal of predictable variation in the psychology of social contracts, some of which is connected to life-cycle processes, and some of which is connected to involvement in monetized social contracts. These relationships cannot falsify the bounded-rational choice prediction but they do open up the avenues for further integrated research (Cosmides et al. 1992).

John P. Ziker is professor of Anthropology at Boise State University. His research with indigenous smallnumber peoples in Siberia has been featured in Science, Human Nature, Human Ecology, Nomadic Peoples, and Ecology of Food and Nutrition. He has conducted fieldwork in the Taimyr Autonomous Region, the north Baikal region, and the Tuva Republic.

\section{Acknowledgments}

I would like to thank the participants of the games in Ust'-Avam, as well as those who acted as research assistants. Funding for this research was provided by the Max Planck Institute for Social Anthropology, Halle (Saale). Funding for the analysis of the experimental games was provided by National Science Foundation in the United States (BCS 0136761). This article is based on work supported by the National Science Foundation under Grant OPP 0631970. I thank Joachim Görlich, Alexander King, and Brian Donahoe for constructively critical comments.

\section{Notes}

1. In comparison with utility maximization, the concept of "rate maximization" is not very common. In common language and thinking, I argue that there is much interest in maximizing profits (or rates). Stockholders are interested in maximal profits, and economies are measured in terms of net jobs created and the gross domestic product. An important measure in Russia is the total wheat harvest.

2. One assumption of rational choice theory is that complex social phenomena can be explained in terms of the elementary individual actions of which they are composed; another assumption is that people calculate the likely costs and benefits of any action before deciding what to do, and that people will choose to perform actions where the benefits outweigh the costs (Scott 2000).

3. Dalton (1971) suggests two other meanings of the concept of rational economic behavior. The second follows Firth (1951), who took a bounded rationality position in which actions are understood as rational if we understand the social system, including the social goals and institutions, such as feasts or meat sharing, which 
This is an author-produced, peer-reviewed version of this article. The final, definitive version of this document can be found online at Sibirica, published by Berghahn Journals. Copyright restrictions may apply. doi: 10.3167/sib.2015.140104

can function to create longer-term stability. Dalton argues that this meaning is tautological because no actions are irrational. Dalton's third definition (1971: 987) of rational economic behavior is "understandable behavior in light of known goals and values of the person behaving," which he argued is also a tautology.

4. For more detail on proximate and ultimate causation, see Cronk (1991: 29) and Daly and Wilson (1983: 17).

5. Social, economic, and political sciences have developed along parallel lines in recent decades to study the importance of social structures, as well as the facilitation or constraints these structures provide for individual action-versus the generative power of individual decisions and actions (through practice)—and their intended or unintended consequences in terms of social structure (Rutz 1977).

6. Peterson argues that at least four elements seem important to the allocation and circulation of resources in the domestic moral economy: 1 . An ethic of generosity informed by a social pragmatics of demand sharing; 2 . Embeddedness in a universal system of kin classification that requires a flow of goods and services to produce and reproduce social relationships; 3. Personhood constituted through relatedness but valuing an egalitarian autonomy; 4. Emphasis on polite indirectness in interaction because open refusal is a rejection of relatedness.

7. Prior to about 1865, thinkers on logic commonly had divided arguments into two subclasses: a class of deductive arguments (i.e., necessary inferences) and a class of inductive arguments (i.e., probable inferences). Peirce differentiated inductive and abductive inferences within a class of probable inferences. Abduction and deduction have something in common however. Both contribute to conceptual or theoretical understanding of a phenomenon. Induction adds quantitative detail to our conceptual-theoretical knowledge.

8. General information on the Dolgans and the Nganasans can be found in Wixman (1984) and Levin and Potapov (1964). Soviet ethnographic descriptions of the traditional economies of the Dolgans (Popov 1937, 1964) and Nganasans (Popov 1963, 1966), as well as of their ethnic origins (Dolgikh 1962, 1963), suffer from a rigid Marxist theoretical approach. Census information from the 1920s, upon which many of these Soviet accounts were based, can provide valuable information from which less ethnocentric histories of economy, ecology and identity can be developed today (Anderson 2000; Ziker 2005, 2011).

9. The project “The Roots of Human Sociality: An Ethno-Experimental Exploration of the Foundations of Economic Norms in 16 Small-Scale Societies” was funded by the National Science Foundation (BCS 0136761).

10. Detailed statistical analysis of the game results are presented in Ziker (2014).

11. No other independent variables were significantly correlated with MAOs except the number of examples read. The larger number of examples read, there was an increase in the MAO. A similar finding was made with Player 1 offers in the DG.

\section{References}

Anderson, David G. 2000. Identity and Ecology in Arctic Siberia: The Number One Reindeer Brigade. Oxford: Oxford University Press.

Axelrod, Robert, and William D. Hamilton. 1981. “The Evolution of Cooperation.” Science 211(4489): 13901396.

Barnard, Alan. 2002. “The Foraging Mode of Thought.” Senri Ethnological Series 60: 5-24.

Barnard, Alan. 2004. "Mutual Aid and the Foraging Mode of Thought: Re-reading Kropotkin on the Khoisan." Social Evolution and History 3(1): 3-21.

Blok, Sergey V., Douglas L. Medin, and Daniel L. Osherson. 2007. “Induction as Conditional Probability Judgment.” Memory \& Cognition 35(6): 1353-1364.

Bloom, Paul, and Tim P. German. 2000. "Two Reasons to Abandon the False Belief Task as a Test of Theory of Mind.” Cognition 77(2000): B25-B31.

Borgerhoff-Mulder, Monique, and Peter Coppolillo. 2005. Conservation: Linking Ecology, Economics, and Culture. Princeton: Princeton University Press.

Bourdieu, Pierre. 1977. Outline of a Theory of Practice. New York: Cambridge University Press.

Bowles, Samuel, and Herbert Gintis. 1998. "The Moral Economy of Communities: Structured Populations and the Evolution of Pro-Social Norms.” Evolution and Human Behavior 19(1): 3-25.

Boyer, Pascal. 1994. The Naturalness of Religious Ideas: A Cognitive Theory of Religion. Berkeley: University of California Press.

Brightman, Robert. 1993. Grateful Prey: Rock-Cree Human Animal Relationships. Berkeley: University of California Press.

Burch, Robert. 2010. “Charles Sanders Peirce.” In The Stanford Encyclopedia of Philosophy, ed. Edward N. Zalta. http://plato.stanford.edu/archives/fall2010/entries/peirce/ (accessed 6 August 2012). 
This is an author-produced, peer-reviewed version of this article. The final, definitive version of this document can be found online at Sibirica, published by Berghahn Journals. Copyright restrictions may apply. doi: 10.3167/sib.2015.140104

Carnap, Rudolf. 1946. "Remarks on Induction and Truth.” Philosophy and Phenomenological Research 6(4): 590-602.

Cosmides, Leda, and John Tooby. 1989. "Evolutionary Psychology and the Generation of Culture, Part II, Case Study: A Computational Theory of Social Exchange.” Ethology and Sociobiology 10(1-3): 51-97.

Cosmides, Leda, John Tooby, and Jerome H. Barkow. 1992. "Introduction: Evolutionary Psychology and Conceptual Integration.” Pp. 3-15 in The Adapted Mind, ed. Jerome H. Barkow, Leda Cosmides, and John Tooby. New York: Oxford University Press. Cronk, Lee. 1991. "Human Behavioral Ecology.” Annual Reviews of Anthropology 20: 25-53.

Dalton, George. 1971. “Comment on Ortiz’s Review of Economic Anthropology.” American Anthropologist 73(4): 986-989.

Daly, Martin I., and Margo Wilson. 1983. Sex, Evolution, and Behavior: Adaptations for Reproduction. 2nd ed. Boston, MA: Willard Grant.

Dolgikh, B.O. 1962. “The Origins of the Nganasans: Preliminary Remarks.” Pp. 220-299 in Studies in Siberian Ethnogenesis, ed. Henry N. Michael. Toronto: Arctic Institute of North America, University of Toronto.

Dolgikh, B.O. 1963. “Proiskhozhdenie Dolgan.” PP. 92-141 in Sibirskii Etnograficheskii Sbornik V, Trudy Instituta Etnografii im. N.N. Miklukho-Maklaia. Novaia Seriia 84. Moscow: Academy of Sciences Publishers.

Ensminger, J., and J. Henrich, eds. 2014. Experimenting with Social Norms: Fairness and Punishment in CrossCultural Perspective. New York: Russell Sage Foundation.

Fehr, Ernst, and Urs Fischbacher. 2002. "Why Social Preferences Matter: The Impact of Non-Selfish Motives on Competition, Cooperation and Incentives.” Economic Journal 112(478): C1-C33.

Fehr, Ernst, and Klaus M. Schmidt. 1999. “A Theory of Fairness, Competition, and Cooperation.” Quarterly Journal of Economics 114(3): 817-868.

Firth, Raymond. 1951. Elements of Social Organization. London: Watts.

Fondahl, Gail, Olga Labeznik, and Greg Poelzer 2000. “Aboriginal Territorial Rights and the Sovereignty of the Sakha Republic.” Post-Soviet Geography and Economics 41(6): 401-417.

Fortes, Meyer. 1958. “Introduction.” Pp. 1-14 in The Development Cycle in Domestic Groups, ed. Jack Goody. Cambridge: Cambridge University Press.

Frank, Robert H. 1988. Passions within Reason: The Strategic Role of the Emotions. New York: W.W. Norton.

Frydman, Roman, and Michael D. Goldberg. 2007. Imperfect Knowledge Economics: Exchange Rates and Risk. Princeton: Princeton University Press.

Gell, Alfred. 1998. Art and Agency. An Anthropological Theory. Oxford: Clarendon Press.

Gerrans, Philip. 2002. “The Theory of Mind Module in Evolutionary Psychology.” Biology and Philosophy 17(3): 305-321.

Gigerenzer, Gerd, and Reinhard Selten. 2002. "Rethinking Rationality.” Pp. 1-12 in Bounded Rationality: The Adaptive Toolbox, ed. Gerd Gigerenzer and Reinhard Selten. Boston: MIT Press.

Gintis, Herbert. 2000. Game Theory Evolving: A Problem-Centered Introduction to Modeling Strategic Interaction. Princeton: Princeton University Press.

Gracheva, G.N. 1983. Traditsionnoe mirovozzrenie okhotnikov Taimyra (na materialakh Nganasan XIVnachala $X X$ v.). Leningrad: Nauka.

Henrich, Joseph, Robert Boyd, Samuel Bowles, Colin F. Camerer, Ernst Fehr, Herbert Gintis, and Robert McElreath. 2004. “Overview and Synthesis.” Pp. 8-54 in Foundations of Human Sociality, ed. Joseph Henrich, Robert Boyd, Samuel Bowles, Colin Camerer, Eernst Fehr, and Herbert Gintis. Oxford: Oxford University Press.

Henrich, Joseph, Jean Ensminger, Richard Mc Elreath, Abigail Barr, Clark Barrett, Alexander Bolyanatz, Juan Camilo Cardenas, Michael Gurven, Edwins Gwako, Natalie Henrich, Carolyn Lesorogol, Frank Marlowe, David Tracer, and John Ziker. 2010. "Markets, Religion, Community Size and the Evolution of Fairness and Punishment.” Science 327(5972): 1480-1484.

Henrich, Joseph, Richard McElreath, Abigail Barr, Jean Ensminger, Clark Barrett, Alexander Bolyanatz, Juan Camilo Cardenas, Michael Gurven, Edwins Gwako, Natalie Henrich, Carolyn Lesorogol, Frank Marlowe, David Tracer, and John Ziker. 2006. “Costly Punishment across Human Societies.” Science 312(5781): 1767-1770.

Jensen, Keith, Josep Call, and Michael Tomasello. 2007. “Chimpanzees Are Rational Maximizers in an Ultimatum Game.” Science 318(5847): 107-109.

Kahneman, Daniel, Jack L. Knetsch, and Richard H. Thaler. 1986. "Fairness and the Assumptions of Economics.” Journal of Business 59(4), Part 2: The Behavioral Foundations of Economic Theory: S285-S300.

Karp, Ivan. 1986. “Agency and Social Theory: A Review of Anthony Giddens.” American Ethnologist 13(1): 131-137. 
This is an author-produced, peer-reviewed version of this article. The final, definitive version of this document can be found online at Sibirica, published by Berghahn Journals. Copyright restrictions may apply. doi: 10.3167/sib.2015.140104

Levin, M.G., and L.P. Potapov, eds. 1964. The Peoples of Siberia. Chicago: University of Chicago Press.

Mauss, Marcel. 1954[1925]. The Gift: Forms and Functions of Exchange in Archaic Societies. London: Cohen and West, Ltd.

McCay, Bonnie J., and James M. Acheson. 1987. "Human Ecology of the Commons.” Pp. 1- 34 in The Question of the Commons: The Culture and Ecology of Communal Resources, ed. Bonnie J. McCay and James M. Acheson. Tucson: University of Arizona Press.

Nash, John F. Jr. 1950. “The Bargaining Problem.” Econometrica 18(2): 155-162.

Nowak, Martin A. 2005. "Five Rules for the Evolution of Cooperation.” Science 314(5805): 1560-1563.

O’Gorman, Rick, David Sloan Wilson, and Ralph R. Miller. 2008. “An Evolved Cognitive Basis for Social Norms.” Evolution and Human Behavior 29(2): 71-78.

Oosterbeek, Hessel, Randolph Sloof, and Gijs van de Kuilen. 2004. "Differences in Ultimatum Game Experiments: Evidence from a Meta-Analysis.” Experimental Economics 7(2): 171-188.

Ostrom, Elinor. 2003. “Towards a Behavior Theory Linking Trust, Reciprocity, and Reputation.” Pp. 19-79 in Trust and Reciprocity: Interdisciplinary Lessons from Experimental Research, ed. Elinor Ostrom and James Walker. New York: Russell Sage Foundation.

Paavola, Sami. 2004. “Abduction through Grammar, Critic, and Methodeutic.” Transactions of the Charles S. Peirce Society: A Quarterly Journal in American Philosophy 40(2): 245-270.

Palfrey, Thomas R., and Howard Rosenthal. 1988. "Private Incentives in Social Dilemmas: The Effects of Incomplete Information and Altruism.” Journal of Public Economics 35(1988): 309-322.

Peterson, Nicolas. 2002. "From Mode of Production to Moral Economy: Sharing and Kinship in Fourth World Social Orders.” Paper presented at the Ninth International Conference on Hunting and Gathering Societies, Edinburgh, 9-13 September.

Popov, A.A. 1937. “Okhota i Rybolovstvo u Dolgan.” Pp. 147-206 in Pamiati V. G. Bogoraza (1865-1936), Sbornik Statei. Moscow: Izdatel’stvo Akademii Nauk SSSR.

Popov, A.A. 1963. “The 'Kuoika,' Guardian Spirits of Family and Clan among the Nganasan.” Arctic Anthropology 1(2): 122-130.

Popov, A.A. 1964. “The Dolgans.” Pp. 655-669 in The Peoples of Siberia, ed. M. G. Levin and L. P. Potapov. Chicago: University of Chicago Press.

Popov, A.A. 1966. The Nganasan: The Material Culture of the Tavgi Samoyeds. Bloomington: Indiana University Press.

Roth, Alvin. E., Vesna Prasnikar, Masahiro Okuno-Fujiwara, and Shmuel Zamir. 1991. "Bargaining and Market Behavior in Jerusalem, Ljubljana, Pittsburgh, and Tokyo: An Experimental Study.” American Economic Review 81(5): 1068-1095.

Ruttan, Lore M. 1998. “Closing the Commons: Cooperation for Gain or Restraint?” Human Ecology 26(1): 4366.

Rutz, Henry J. 1977. "Individual Decisions and Functional Systems: Economic Rationality and Environmental Adaptation.” American Ethnologist 4(1): 156-174.

Sahlins, Marshall. 1972. Stone Age Economics. New York: Aldine de Gruyter.

Scott, James C. 1976. The Moral Economy of the Peasant: Rebellion and Subsistence in Southeast Asia. New Haven, CT: Yale University Press.

Scott, John. 2000. "Rational Choice Theory.” Pp. 126-138 in Understanding Contemporary Society: Theories of the Present, ed. Gary K. Browning, Abigail Halcli, and Frank Webster. London: Sage.

Tooby, John, and Leda Cosmides. 1992. “The Psychological Foundations of Culture.” Pp. 19-136 in The Adapted Mind, ed. Jerome H. Barkow, Leda Cosmides, and John Tooby. New York: Oxford University Press.

Trawick, Paul, B. 2001. "Successfully Governing the Commons: Principles of Social Organization in an Andean Irrigation System.” Human Ecology 29(1): 1-25.

Widlok, Thomas. 2002. “Towards a Theoretical Approach to the Moral Dimension of Access.” Max Planck Institute for Social Anthropology Working Paper No. 37.

Widlok, Thomas. 2004. "Sharing by Default? Outline of an Anthropology of Virtue.” Anthropological Theory 4(1): 53-70.

Wiessner, Polly. 2005. "Norm Enforcement among the Ju/'hoansi Bushmen: A Case of Strong Reciprocity?” Human Nature 16(2): 115-145.

Wixman, Ronald. 1984. The Peoples of the USSR: An Ethnographic Handbook. Armonk, NY: M.E. Sharpe.

Woodburn, James. 1998. "Sharing Is Not a Form of Exchange: An Analysis of Property- Sharing in ImmediateReturn Hunter-Gatherer Societies.” Pp. 48-63 in Property Relations, ed. C.M. Hann. Cambridge: Cambridge University Press.

Yamagishi, Toshio, and Nobuhiro Mifune. 2009. "Social Exchange and Solidarity: In-Group Love or OutGroup Hate?” Evolution and Human Behavior 30(4): 229-237. 
This is an author-produced, peer-reviewed version of this article. The final, definitive version of this document can be found online at Sibirica, published by Berghahn Journals. Copyright restrictions may apply. doi: 10.3167/sib.2015.140104

Ziker, John P. 2002. Peoples of the Tundra: Northern Siberians in the Post-Communist Transition. Prospect Heights, IL: Waveland Press.

Ziker, John P. 2003. “Assigned Territories, Family/Clan/Communal Holdings, and Common- Pool Resources in the Taimyr Autonomous Region, Northern Russia.” Human Ecology 31(3): 331-368.

Ziker, John P. 2005. “The Central Taimyr Lowlands in 1926/27: Identity and Settlement Pattern of the Native Peoples.” Pp. 79-87 Turukhanskaia ekspeditsiia pripoliarnoi perepisi: Etnografiia i demografiia malochislennykh narodov severa, ed. David G. Anderson. Krasnoyarsk: Polikor. [In Russian.]

Ziker, John P. 2007. "Subsistence and Food Sharing in Northern Siberia: Social and Nutritional Ecology of the Dolgan and the Nganasan.” Ecology of Food and Nutrition 46(5/6): 445-467.

Ziker, John P. 2011. "Subsistence and Residence in the Putoran Uplands and Taimyr Lowlands in the 1920s." Pp. 244-267 in The 1926/27 Soviet Polar Census Expeditions A Re-discovery of Russia's Northern Peoples and Their Lands, ed. David G. Anderson. New York: Berghahn Books.

Ziker, John P. 2014. "Subsistence and Sharing in Northern Siberia: Experimental Economics with the Dolgan and Nganasan.” Pp. 337-356 in Fairness and Punishment in Cross- Cultural Perspective, ed. Jean Ensminger and Joseph Henrich. New York: Russell Sage Foundation.

Ziker, John P., Kersti M. Harter, Eric C. Kennedy, and Sweat Skyler. 2006. “Trust, Reciprocity, and Resources: Using Experimental Games to Understand Perspectives of College Students.” Poster presented to Human Behavior and Evolution Society Annual Meeting, University of Pennsylvania and Drexel University, Philadelphia, 7- 11 June.

Ziker, John P., and Michael Schnegg. 2005. "Food Sharing at Meals: Kinship, Reciprocity and Clustering in the Taimyr Autonomous Okrug, Northern Russia.” Human Nature 16(2): 64-96. 